Arq. Bras. Med. Vet. Zootec., v.66, n.6, p.1831-1838, 2014

\title{
Biomassa de Rubrivivax gelatinosus na criação de frangos de corte: desempenho animal e cor dos produtos
}

\author{
[Biomass of Rubrivivax gelatinosus in broiler chicken feeding: animal \\ performance and color of products] \\ S.V. Avanço ${ }^{1}$, E.H.G. Ponsano ${ }^{2}$, M. Garcia Neto ${ }^{2}$, M.F. Pinto ${ }^{2}$ \\ ${ }^{1}$ Aluno de pós-graduação - Faculdade de Medicina Veterinária de Araçatuba - UNESP - Araçatuba, SP \\ ${ }^{2}$ Faculdade de Medicina Veterinária de Araçatuba - UNESP - Araçatuba, SP
}

\begin{abstract}
RESUMO
A bactéria Rubrivivax gelatinosus tem sido utilizada experimentalmente no tratamento despoluente de efluentes industriais de abatedouros de aves e peixes, originando uma biomassa contendo pigmentos carotenoides, substâncias que possuem a capacidade de conferir cor aos alimentos e proteger contra reações oxidativas. Este trabalho teve por objetivo verificar o efeito da biomassa de $R$. gelatinosus adicionada à alimentação de frangos de corte sobre o desempenho animal e a cor de carne e pele. Duzentos pintos machos Cobb 500 foram distribuídos aleatoriamente em 20 boxes para receber, do $36^{\circ}$ ao $45^{\circ}$ dia de criação, quatro tratamentos com diferentes quantidades de biomassa na ração (T1 [controle] - 0g/kg; T2 - 1g/kg; T3 - 2g/kg; T4 - 3g/kg), em cinco repetições. As pesagens de aves e rações para a análise de desempenho foram feitas no início da criação e ao fim de cada período de crescimento. Ao final do experimento (45 dias), 20 aves de cada tratamento foram abatidas para a determinação da cor objetiva ( $\mathrm{L}$ - luminosidade, $\mathrm{C}$ - saturação, $\mathrm{h}$ - tom) em pele e carne de peito e coxa. Os resultados obtidos foram submetidos à ANOVA, teste t para a comparação múltipla de médias e análise de regressão com nível de significância de $5 \%$. O ganho de peso e o consumo das aves não diferiram estatisticamente entre si $(\mathrm{P}>0,05)$, enquanto o índice de conversão alimentar foi superior para o T1. A luminosidade da carne e da pele aumentou significativamente nos tratamentos que receberam a biomassa. O tom da cor em carne e pele aumentou em direção ao amarelo até a concentração de $2 \mathrm{~g}$ de biomassa por kg de ração, ao passo que, na concentração de $3 \mathrm{~g} / \mathrm{kg}$, o aumento foi em direção à tonalidade vermelha. Somente na carne da coxa a saturação da cor sofreu influência da presença da biomassa na dieta. Concluiu-se que, até a proporção de $3 \mathrm{~g} / \mathrm{kg}$, a biomassa não prejudicou o desempenho e foi eficiente em pigmentar a pele e a carne de frangos de corte.
\end{abstract}

Palavras-chave: aditivo alimentar, carotenoides, pigmentação, produto biotecnológico, xantofilas

\begin{abstract}
The phototrophic bacterium Rubrivivax gelatinosus has been used experimentally for the depollution of industrial effluents from broiler and fish slaughterhouses, resulting in a biomass containing oxycarotenoids, substances that impart color and protection against to oxidative reactions. This work aimed to check the effect of R. gelatinosus biomass added into broiler chickens' feed on animal performance and meat/skin color. Two hundred Cobb 500 male chicks were randomly divided into 20 boxes to receive, from the $36^{\text {th }}$ to the $45^{\text {th }}$ day of rearing, 4 treatments with different amounts of biomass in the diets (T1 [control] - 0g/kg; T2 - 1g/kg; T3 $2 \mathrm{~g} / \mathrm{kg} ; \mathrm{T} 4-3 \mathrm{~g} / \mathrm{kg}$ ), in 5 replicates. Chickens and rations were weighted at the beginning of the rearing time and at the end of each growth phase to assess animal performance. At the end of the experiment (45 days), 20 birds from each repetition were slaughtered for the evaluation of the objective color ( $L$ - lightness, $C$ - chroma, $h$ hue) on skin and meat of breast and thigh. Statistical analyses comprised ANOVA, t test for means comparison and regression analysis, at 5\% significance level. Weight gain and feed consumption did not differ statistically $(P>0.05)$, while feed conversion was better for T1. Lightness of meat and skin increased significantly in the treatments with the biomass supplementation. Hue angle of meat and skin increased towards yellow until $2 \mathrm{~g}$ biomass $/ \mathrm{kg}$ and towards red at $3 \mathrm{~g} / \mathrm{kg}$. Chroma was only influenced by the presence of the biomass in thigh meat. It was concluded that the addition of the biomass up to $3 \mathrm{~g} / \mathrm{kg}$ was not harmful to birds' performance and was efficient to cause changes in the color of broiler skin and meat.
\end{abstract}

Keywords: feed additive, carotenoids, pigmentation, biotechnological product, xanthophylls

Recebido em 4 de fevereiro de 2014

Aceito em 2 de abril de 2014

E-mail: sauloavanco@hotmail.com 


\section{INTRODUÇÃO}

A preocupação com a destinação e o tratamento dos dejetos orgânicos, domésticos ou industriais, é de fundamental importância quando se objetiva a sustentabilidade ao longo da cadeia produtiva. Alguns pesquisadores têm utilizado recursos biotecnológicos para o tratamento de efluentes industriais, tais como o uso de bactérias fotossintetizantes, como Rubrivivax gelatinosus, que possuem a capacidade de reduzir a carga poluente desses resíduos (Ponsano et al., 2002a, 2003, 2008; Lima et al., 2011).

Lima et al. (2011) caracterizaram o crescimento de $R$. gelatinosus em efluente de indústria de pescado, observando uma redução da Demanda Química de Oxigênio em 52\%. Ponsano et al. (2002a) isolaram e caracterizaram quatro culturas de $R$. gelatinosus a partir de águas residuárias provenientes do abate de frangos e identificaram seus carotenoides como sendo da série espiriloxantina alternativa. Posteriormente, Ponsano et al. (2003) investigaram a composição centesimal da biomassa de $R$. gelatinosus e encontraram elevada quantidade de proteínas e aminoácidos essenciais. Os carotenoides da biomassa de $R$. gelatinosus foram capazes de promover a elevação da intensidade da cor vermelha de gemas de ovos quando adicionados à ração de galinhas poedeiras (Polonio et al., 2010).

Os carotenoides são divididos quimicamente em dois grupos: os carotenos e as xantofilas. Os carotenos são hidrocarbonetos puros, geralmente de cor alaranjada, enquanto as xantofilas apresentam em sua constituição átomos de oxigênio e são de coloração amarela e vermelha, sendo também chamadas de oxicarotenoides (Melendez-Martinez et al., 2004; Bhosale e Bernstein, 2005). Sua produção na natureza ocorre em plantas e, em menor escala, em leveduras, fungos, algas e bactérias (Bhosale e Bernstein, 2005). Os carotenoides são os compostos responsáveis pela pigmentação de aves e peixes, em particular a classe das xantofilas, predominante na alimentação dos animais e, também, por conferir as cores amarela, laranja e vermelha aos vegetais (Castañeda et al., 2005).

A pigmentação de pele e pernas de frangos e da gema de ovos é proveniente da ingestão de compostos carotenoides presentes nos ingredientes da ração, tais como milho, farelo de glúten de milho e alfafa desidratada, assim como dos aditivos pigmentantes utilizados (PérezVendrell et al., 2001). Animais saudáveis absorvem os pigmentos da dieta e os transportam ao tecido subcutâneo onde eles se depositam; por isso, animais com infecções intestinais ou parasitárias apresentam absorção intestinal deficiente e, como consequência, pigmentação irregular (Tyczkowski et al., 1991).

Para obter a coloração valorizada pelos consumidores em alimentos como ovos e carne de aves e peixes, é possível adicionar à ração dos animais uma combinação de carotenoides sintéticos para conferir pigmentação amarela (apo-ester, luteína, zeaxantina) e vermelha (cantaxantina, citranaxantina, capsantina, capsoburina) (Castañeda et al., 2005). Portanto, a intensidade de cor amarela e/ou vermelha pode ser controlada pela concentração e pelo tipo de xantofilas na dieta (Chen e Yang, 1992; Lai et al., 1996).

Este trabalho teve por objetivo verificar o efeito da biomassa de $R$. gelatinosus, adicionada à alimentação de frangos de corte, sobre o desempenho animal e a cor dos produtos, tendo em vista que seu processo de obtenção representa uma alternativa de tratamento para subprodutos de indústrias de alimentos, o que contribui para a sustentabilidade ao longo do processo produtivo.

\section{MATERIAL E MÉTODO}

O experimento foi conduzido no galpão experimental do Setor de Zootecnia da Faculdade de Medicina Veterinária da UNESP, Campus de Araçatuba. Duzentos pintos machos de um dia de idade da linhagem Cobb 500 foram alocados aleatoriamente em 20 boxes telados $(0,6 \times 1,5 \times$ 3,0 m - a x l x c), com cama de maravalha, dotados de comedouros e bebedouros de altura regulável. Cada box correspondeu a uma parcela experimental (4 tratamentos e 5 repetições), composta por 10 aves.

Para a formulação das rações experimentais (Tab. 1), os ingredientes foram adquiridos junto ao comércio varejista local, e seu balanceamento foi realizado por meio do programa PPFR (http://sites.google.com/site/ppfrprogramforfeedf ormulation/), conforme as exigências 
nutricionais recomendadas por Rostagno et al. (2011). O fornecimento de ração e de água foi feito à vontade durante todo o período de criação, de 45 dias. $\mathrm{O}$ aquecimento foi feito de forma intermitente com lâmpadas incandescentes de $250 \mathrm{~W}$ apenas durante os 15 primeiros dias de criação.

Tabela 1. Composições das rações basais para frangos de corte nas diferentes fases de crescimento e com diferentes concentrações de $R$. gelatinosus

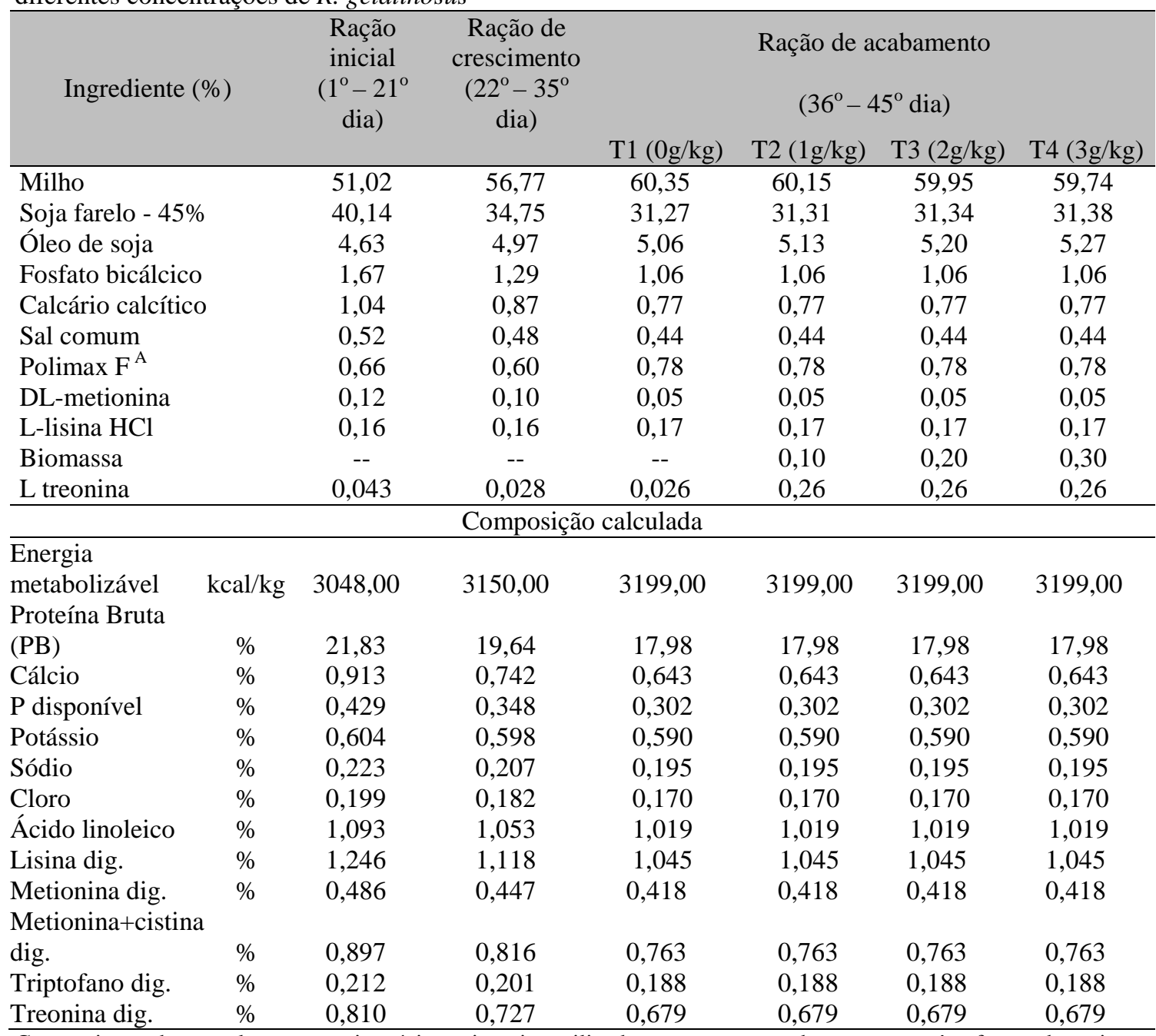

Composição dos suplementos vitamínico-minerais utilizados nas rações durante as três fases de criação (quantidade/kg do produto): Inicial: vit. A - 1.670.000 U.I; vit. D3 - 335.000 U.I; vit. E - 2.500mg; vit. K3 - 417mg; vit. B1 - 250mg; vit. B2 - 835 mg; vit. B6 - 250mg; vit. B12 - 2.000mcg; ácido fólico - 100mg; biotina - 9mg; niacina - 5.835mg; pantotenato de cálcio - 1.870mg; Cu - 1.000mg; Co - 17mg; I - 170mg; Fe - 8.335mg; Mn - 10.835mg; Zn - 7.500mg; Se - 35 mg; Cloreto de Colina 50\% - 116.670mg; Metionina - 250.000mg; Coccidiostático - 13.335mg; Promotor de Crescimento - 13.335mg; Antioxidante - 2.000mg. Crescimento: vit. A - 1.335.000 U.I; vit. D3 300.000 U.I; vit. E - 2.000mg; vit. K3 - 335mg; vit. B1 - 167mg; vit. B2 - 670mg; vit. B6 - 170mg; vit. B12 1.670mcg; ácido fólico - 67mg; biotina - 7mg; niacina - 4.670mg; pantotenato de cálcio - 1.870mg; Cu - 1.000mg; Co - 17mg; I - 170mg; Fe - 8.335mg; Mn - 10.835mg; Zn - 7.500mg; Se - 35mg; Cloreto de Colina 50\% - 83.340mg; Metionina - 235.000mg; Coccidiostático - 10.000mg; Promotor de Crescimento - 10.000mg; Antioxidante - 2.000mg. Terminação: vit. A - 1.670 .000 U.I; vit. D3 - 335.000 U.I; vit. E - 2.335mg; vit. K3 - 400mg; vit. B1 - 100mg; vit. B2 - 800mg; vit. B6 - 200mg; vit. B12 - 2.000 mcg; ácido fólico - 67mg; biotina - 7mg; niacina - 5.670mg; pantotenato de cálcio - 2.000mg; Cu - 2.000mg; Co - 27mg; I - 270mg; Fe - 16.670mg; Mn - 17.335mg; Zn $12.000 \mathrm{mg}$; Se - 70mg; Cloreto de Colina 50\% - 100.000mg; Metionina - 235.000mg; Antioxidante - 2.000mg. Dosagem de $6 \mathrm{~kg}$ do produto por tonelada de ração. 
Quatro tipos de rações experimentais, contendo diferentes concentrações de biomassa bacteriana (T1 [controle] - 0g/kg; T2 - 1g/kg; T3 - 2g/kg; T4 - 3g/kg), constituíram os 4 tratamentos, que foram aplicados durante o período de acabamento (do $36^{\circ}$ ao $45^{\circ} \mathrm{dia}$ ) (Tab. 1). Para o preparo das rações experimentais, a biomassa foi primeiro dissolvida em óleo de soja para, depois, ser incorporada à ração basal de acabamento, com o auxílio de um misturador de ração horizontal com capacidade para $250 \mathrm{~kg}$.

As aves e as rações foram pesadas no início da criação e ao final de cada período $\left(21^{\circ}, 35^{\circ}\right.$ e $45^{\circ}$ dia) para a análise de desempenho, que incluiu ganho de peso (g/ave/período), consumo de ração (g/ave/período) e conversão alimentar. A aplicação das dietas experimentais ocorreu após a constatação de que os animais das diferentes parcelas estavam todos nas mesmas condições de desenvolvimento (não eram significativamente distintos quanto aos parâmetros zootécnicos).

No último dia de criação, 80 animais (4 aves de cada parcela experimental) foram amostrados ao acaso, identificados nos pés com anilhas plásticas e, após 8 horas de jejum alimentar, foram abatidos segundo as normas sanitárias legais brasileiras (Brasil, 1998), depenados automaticamente, eviscerados manualmente, resfriados em chiller por uma hora e drenados por aproximadamente 10 minutos.

A determinação objetiva da cor foi realizada diretamente sobre a carne e a pele do peito e das coxas, pela medição dos atributos L (Luminosidade), C (saturação) e h (tom), utilizando-se colorímetro portátil Mini Scan XE Plus calibrado com padrões branco e preto. Para a obtenção do valor médio, foram realizadas três leituras consecutivas em cada corte dos lados esquerdo e direito. No espaço de cor LCh, L representa a luminosidade do produto, expressa por valores que vão de 0 (negro absoluto) a 100 (branco absoluto). O valor de $\mathrm{C}$ representa a saturação das cores numa escala de 0 (cinza, branco ou negro) a 100 (cores puras e intensas). Por fim, o valor de h, que representa o tom das cores, é medido em graus (medida angular), sendo $0^{\circ}$ - vermelho, $90^{\circ}$ - amarelo, $180^{\circ}$ - verde, e $270^{\circ}$ - azul, passando por tons intermediários entre esses valores.

Os dados foram testados quanto à normalidade dos erros e à homogeneidade de variâncias. Os resultados foram submetidos à ANOVA, teste $\mathrm{t}$ para a comparação múltipla das médias dos dados de desempenho e cor, e análise de regressão para as concentrações de biomassa e os dados e cor. As análises estatísticas foram realizadas utilizando-se o programa SAS 9.2 (Statistical..., 2008) licenciado para a Universidade Estadual Paulista Júlio de Mesquita Filho (Site = 70014138; validade 28/07/2011 a 27/05/2012). O nível de significância adotado foi de $5 \%$ (Zar, 1999).

\section{RESULTADOS E DISCUSSÃO}

Os parâmetros de desempenho avaliados durante o período de acabamento $\left(36^{\circ}-45^{\circ}\right.$ dia) estão apresentados na Tabela 2 e mostram que somente o índice de conversão alimentar foi afetado significativamente pela inclusão da biomassa. Nesse período, o grupo alimentado com ração não adicionada da biomassa de $R$. gelatinosus (T1) apresentou o melhor índice de conversão alimentar, que não diferiu significativamente do grupo que teve $2 \mathrm{~g}$ de biomassa adicionada à sua ração (T3). Os demais parâmetros zootécnicos não foram afetados significativamente, demonstrando que a biomassa tem pouca influência sobre o desempenho. Além disso, a ausência de diferença significativa entre a conversão alimentar dos grupos T2, T3 e T4 confirma o bom desempenho dos animais, mesmo quando alimentados com a biomassa nas concentrações avaliadas.

Tabela 2. Desempenho das aves dos diferentes tratamentos no período de acabamento $\left(36^{\circ}-45^{\circ}\right.$ dia)

\begin{tabular}{cccc} 
& \multicolumn{3}{c}{ média \pm EPM } \\
\cline { 2 - 4 } Concentração de biomassa $(\mathrm{g} / \mathrm{kg})$ & Ganho de peso $(\mathrm{kg})$ & Consumo (kg/ave) & Conversão alimentar \\
\hline 0 (T1) & $1,184 \pm 0,066$ & $2,125 \pm 0,086$ & $1,808 \pm 0,080 \mathrm{~b}$ \\
1 (T2) & $1,046 \pm 0,031$ & $2,161 \pm 0,046$ & $2,073 \pm 0,079 \mathrm{a}$ \\
(T3) & $1,088 \pm 0,034$ & $2,145 \pm 0,034$ & $1,980 \pm 0,076 \mathrm{ab}$ \\
(T4) & $1,059 \pm 0,053$ & $2,165 \pm 0,039$ & $2,061 \pm 0,097 \mathrm{a}$ \\
CV (\%) & 3,28 & 3,70 & 2,51 \\
\hline
\end{tabular}

Valores na coluna seguidos da mesma letra não diferem estatisticamente entre si $(\mathrm{P}>0,05)$ segundo o teste $\mathrm{t}$. EPM = Erro padrão da média; CV = Coeficiente de variação. 
Esse resultado ratifica o que Ponsano et al. (2004) observaram ao adicionar a biomassa de $R$. gelatinosus à ração de frangos de corte. Por outro lado, esses mesmos pesquisadores observaram que os animais do grupo controle ganharam mais peso do que dois dos três grupos tratados, diferentemente do observado nesta pesquisa, em que nenhum dos grupos diferiu entre si.

Demais pesquisadores que utilizaram outras fontes de carotenoides na dieta de frangos de corte não observaram diferença significativa no desempenho produtivo dos animais (Liufa et al., 1997; Akiba et al., 2001; Pérez-Vendrell et al.,
2001). A ausência de diferenças nos demais parâmetros de desempenho é positiva, pois pressupõe não haver alteração das características sensoriais da ração quando da adição do produto.

Os resultados das análises estatísticas para os atributos da cor em carne e pele estão representados nas Tabelas 3 e 4. A comparação entre as médias demonstrou não haver diferença significativa entre as concentrações de biomassa para as variáveis saturação e tom da pele do peito, luminosidade e saturação da pele da coxa, saturação da carne do peito e tom da carne da coxa $(\mathrm{P}>0,05)$.

Tabela 3. Atributos da cor ( $\mathrm{L}$ - Luminosidade, $\mathrm{C}$ - saturação, $\mathrm{h}$ - tom) para pele do peito e da coxa de frangos de corte alimentados com diferentes níveis de biomassa de $R$. gelatinosus na ração

\begin{tabular}{|c|c|c|c|c|c|c|}
\hline \multirow{2}{*}{$\begin{array}{c}\text { Concentração } \\
\text { de biomassa } \\
(\mathrm{g} / \mathrm{kg})\end{array}$} & \multicolumn{3}{|c|}{ Pele do peito $(\mathrm{X} \pm \mathrm{EPM})$} & \multicolumn{3}{|c|}{ Pele da coxa $(X \pm E P M)$} \\
\hline & $\mathrm{L}$ & $\mathrm{C}$ & $\mathrm{h}$ & $\mathrm{L}$ & C & $\mathrm{h}$ \\
\hline 0 (T1) & $68,16 \pm 0,37 b$ & $16,25 \pm 0,60$ & $68,57 \pm 0,70$ & $71,40 \pm 0,75$ & $13,62 \pm 0,62$ & $70,00 \pm 1,67 \mathrm{ab}$ \\
\hline 1 (T2) & $69,30 \pm 0,21 \mathrm{ab}$ & $15,50 \pm 0,41$ & $69,71 \pm 0,67$ & $72,06 \pm 0,67$ & $13,19 \pm 0,26$ & $71,54 \pm 0,89 \mathrm{ab}$ \\
\hline 2 (T3) & $70,38 \pm 0,67 a$ & $16,63 \pm 0,72$ & $70,09 \pm 0,41$ & $72,88 \pm 0,57$ & $13,06 \pm 0,95$ & $73,18 \pm 1,15 a$ \\
\hline $3(\mathrm{~T} 4)$ & $69,08 \pm 0,57 \mathrm{ab}$ & $16,03 \pm 0,43$ & $68,60 \pm 0,80$ & $72,26 \pm 0,40$ & $12,45 \pm 0,26$ & $69,46 \pm 1,08 b$ \\
\hline CV (\%) & 1,57 & 7,67 & 2,14 & 1,89 & 10,18 & 3,88 \\
\hline
\end{tabular}

Valores na mesma coluna seguidos da mesma letra não diferem estatisticamente entre si $(\mathrm{P}>0,05)$ segundo o teste t. $\mathrm{EPM}=$ Erro padrão da média; CV = Coeficiente de variação.

Tabela 4. Atributos da cor ( $\mathrm{L}$ - Luminosidade, $\mathrm{C}$ - saturação, $\mathrm{h}$ - cor) para carne do peito e da coxa de frangos de corte alimentados com diferentes níveis de biomassa de $R$. gelatinosus na ração

\begin{tabular}{|c|c|c|c|c|c|c|}
\hline \multirow{2}{*}{$\begin{array}{c}\text { Concentração } \\
\text { de biomassa } \\
(\mathrm{g} / \mathrm{kg})\end{array}$} & \multicolumn{3}{|c|}{ Carne do peito (X \pm EPM) } & \multicolumn{3}{|c|}{ Carne da coxa (X \pm EPM) } \\
\hline & $\mathrm{L}$ & $\mathrm{C}$ & $\mathrm{h}$ & $\mathrm{L}$ & $\mathrm{C}$ & $\mathrm{h}$ \\
\hline 0 (T1) & $60,70 \pm 0,86 b$ & $18,75 \pm 0,31$ & $68,87 \pm 0,55 b$ & $57,77 \pm 0,47 \mathrm{ab}$ & $17,44 \pm 0,33 a$ & $62,06 \pm 0,60$ \\
\hline $1(\mathrm{~T} 2)$ & $61,39 \pm 0,67 a b$ & $17,78 \pm 0,36$ & $69,73 \pm 0,42 \mathrm{ab}$ & $56,77 \pm 0,69 b$ & $16,76 \pm 0,35 \mathrm{ab}$ & $60,65 \pm 1,06$ \\
\hline 2 (T3) & $63,39 \pm 0,67 a$ & $18,35 \pm 0,43$ & $71,39 \pm 0,69 a$ & $57,94 \pm 0,87 \mathrm{ab}$ & $16,23 \pm 0,21 b$ & $59,90 \pm 1,38$ \\
\hline $3(\mathrm{~T} 4)$ & $62,44 \pm 0,85 \mathrm{ab}$ & $18,52 \pm 0,34$ & $70,35 \pm 1,09 \mathrm{ab}$ & $58,88 \pm 0,68 \mathrm{a}$ & $16,77 \pm 0,36 \mathrm{ab}$ & $61,66 \pm 1,52$ \\
\hline CV (\%) & 2,78 & 4,40 & 2,35 & 2,69 & 4,27 & 4,36 \\
\hline
\end{tabular}

Valores na mesma coluna seguidos da mesma letra não diferem estatisticamente entre si $(p>0,05)$ segundo o teste t. $\mathrm{EPM}=$ Erro padrão da média; $\mathrm{CV}$ = Coeficiente de variação

Por outro lado, foram encontradas diferenças significativas entre os tratamentos $(\mathrm{P}<0,05)$ para os atributos luminosidade da pele do peito, tom da pele da coxa, luminosidade e tom da carne do peito e luminosidade e saturação da carne da coxa. Nos locais citados, a luminosidade apresentou uma tendência de aumento, o que significa que o uso do produto na alimentação dos frangos tornou a cor da pele e da carne mais claras. Em relação ao tom, o uso do produto nas menores concentrações indicou uma tendência para o aumento do amarelo na pele da coxa e na carne do peito, seguida do aumento em direção ao vermelho, decorrente da aplicação da biomassa na proporção de $3 \mathrm{~g} / \mathrm{kg}$ de ração. Além disso, o uso do produto indicou uma tendência para a diminuição na saturação da cor da carne da coxa. 
A análise de regressão mostrou-se uma boa ferramenta para explicar a influência da biomassa sobre os atributos da cor. Por meio dela, verificou-se haver uma relação linear entre as concentrações de biomassa e a luminosidade e o tom da carne do peito até a dose máxima estudada, de $3 \mathrm{~g} / \mathrm{kg}$, e uma relação quadrática entre as concentrações da biomassa e a saturação da cor da carne da coxa (Fig. 1).

A equação da reta obtida para a luminosidade da carne do peito (Fig. 1a) permite concluir que, para cada aumento de $1 \mathrm{~g}$ de biomassa, há um aumento de 0,7242 na luminosidade, ao passo que a equação da reta obtida para h (Fig. 1b) permite afirmar que a elevação de cada $1 \mathrm{~g}$ de biomassa ocasiona um aumento de 0,6095 no tom da cor. Em um comportamento inverso, pode-se estimar em $1,92 \mathrm{~g} / \mathrm{kg}$ a concentração necessária de biomassa para atingir o valor mínimo da saturação da carne da coxa (Fig. 1c).
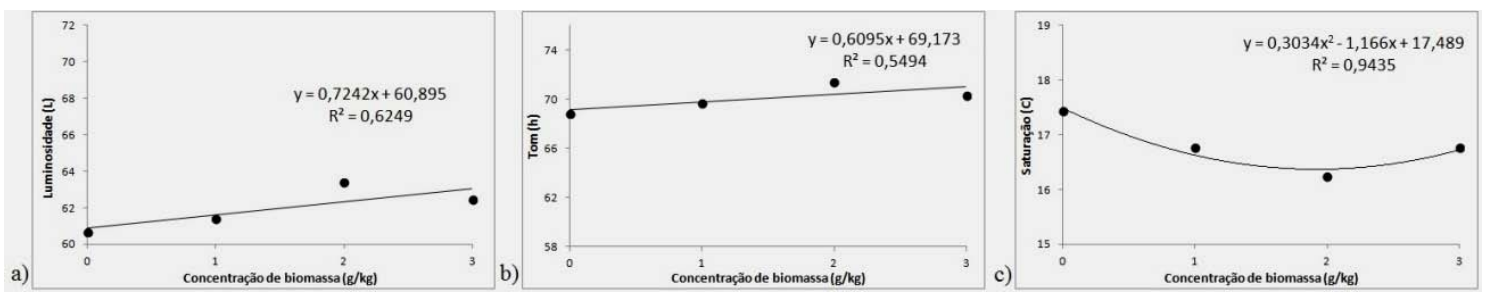

Figura 1. Regressões lineares da luminosidade da carne do peito (a) e do tom da carne do peito (b), regressão quadrática da saturação da cor da carne da coxa (c), respectivas equações das retas e coeficientes de determinação $\left(\mathrm{R}^{2}\right)$.

Para as variáveis luminosidade e tom da pele do peito e tom da pele da coxa, verificou-se um efeito quadrático decorrente da aplicação da biomassa na ração. A adequação do modelo quadrático foi verificada por meio dos coeficientes de determinação $\left(\mathrm{R}^{2}\right)$ (Fig. 2). As doses ótimas estimadas de biomassa na ração para fornecer os valores máximos de cada atributo foram de $1,81 \mathrm{~g} / \mathrm{kg}$ para luminosidade da pele do peito, $1,54 \mathrm{~g} / \mathrm{kg}$ para tom da pele do peito e $1,50 \mathrm{~g} / \mathrm{kg}$ para tom da pele da coxa.
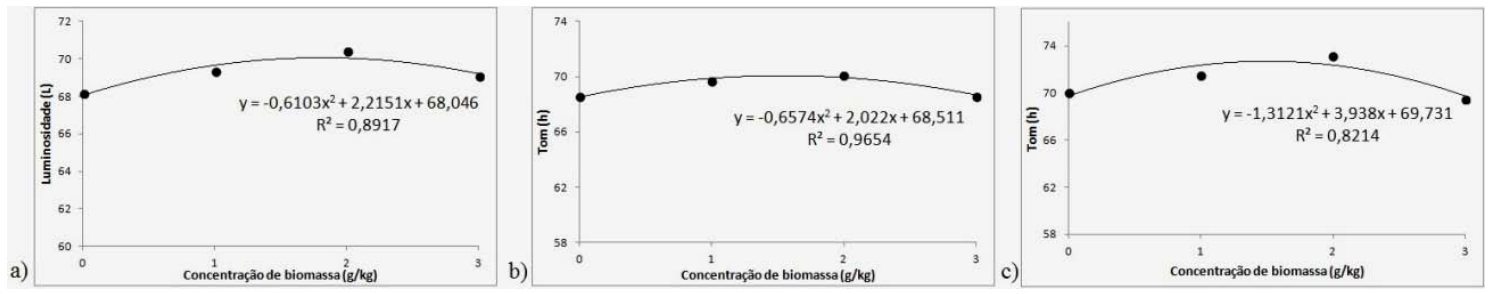

Figura 2. Regressões quadráticas da luminosidade da pele do peito (a), do tom da pele do peito (b), do tom da pele da coxa (c), respectivas equações das retas e coeficientes de determinação $\left(\mathrm{R}^{2}\right)$.

O comportamento dos pigmentos de $R$. gelatinosus frente aos atributos de cor se assemelha ao observado em outras pesquisas tanto com o produto quanto com outros pigmentantes. Ponsano et al. (2004), por exemplo, observaram a redução da luminosidade na pele e na carne de peito e na coxa de frangos de corte nos grupos tratados com a biomassa de $R$. gelatinosus, nas três concentrações utilizadas $(0,075 \mathrm{~g} / \mathrm{kg}, 0,15 \mathrm{~g} / \mathrm{kg}$ e $0,3 \mathrm{~g} / \mathrm{kg})$. Ponsano et al. (2002b), comparando o efeito de $R$. gelatinosus com o de pigmentos sintéticos, observaram que alguns grupos não diferiam do grupo controle em relação a L, cujos valores foram muito semelhantes aos observados nesta pesquisa. Toyomizu et al. (2001), por outro lado, não observaram diferença na luminosidade entre o grupo tratado e o controle, quando adicionaram biomassa das algas Spirulina platensis e $S$. 
máxima, com elevada quantidade de carotenoides, na ração de frangos de corte.

Quanto a C, Ponsano et al. (2004) encontraram valores maiores para os grupos tratados com a maior concentração de biomassa $(0,3 \mathrm{~g} / \mathrm{kg})$ e os menores valores para o grupo controle, tanto para a carne do peito quanto da coxa de frangos. O diferente comportamento desse atributo nas diferentes pesquisas pode ser justificado pela utilização de diferentes rações basais. Enquanto neste experimento utilizou-se ração à base de milho, fonte natural de xantofilas, naquele a ração utilizada era à base de sorgo, em que esses compostos estavam ausentes.

Para h, Ponsano et al. (2004) também observaram aumento da intensidade de amarelo em relação ao grupo controle (sem biomassa bacteriana) na pele e na carne de peito e coxa de frangos. Ponsano et al. (2002b), igualmente, observaram que a biomassa de $R$. gelatinosus elevou a pigmentação do tom amarelo na carne $\mathrm{e}$ na pele, ao passo que os pigmentos sintéticos acentuaram o tom vermelho na carne e na pele de aves. Neste experimento, verificou-se uma elevação de h em direção ao amarelo próximo à concentração de $2 \mathrm{~g} / \mathrm{kg}$, tanto na pele da coxa quanto na carne do peito, seguida de uma diminuição em direção ao vermelho, a partir dessa concentração. Esse achado pode ser explicado pelo fato de que, de acordo com DSM (2004), antes de ocorrer a deposição dos pigmentos vermelhos, é necessário que ocorra a saturação da deposição dos pigmentos amarelados. Portanto, encontrou-se que a concentração de biomassa até $2 \mathrm{~g} / \mathrm{kg}$ de ração é insuficiente para promover a saturação dos pigmentos amarelos, enquanto $3 \mathrm{~g} / \mathrm{kg}$ são capazes de promover a saturação e a subsequente deposição de pigmentos vermelhos.

Toyomizu et al. (2001) também observaram elevação do tom de amarelo no peito e na coxa de frangos de corte tratados com a biomassa da alga Spirulina platensis. A comparação da adição de pigmentos sintéticos e naturais feita por Castañeda et al. (2005) também aponta para elevação da intensidade de amarelo na pele do peito de frangos no grupo tratado com pigmentantes naturais (extrato da flor do cravo-amarelo) e aumento da intensidade de vermelho para pigmentantes sintéticos. Esses pesquisadores também investigaram a coloração da carne de frangos de corte no instante do abate, 15 e 120 minutos post-mortem, e observaram queda da intensidade de vermelho e elevação da intensidade de amarelo, devido à perda de sangue e à solidificação da gordura subcutânea. De acordo com esses autores, a absorção de pigmentos sintéticos ocorre de forma mais eficaz, porém são os pigmentos naturais que detêm melhor capacidade de se depositar nos tecidos.

De modo geral, pode-se dizer que, assim como ocorre com outros pigmentantes, o efeito da biomassa sobre a definição da cor dos cortes cárneos está relacionado a diversos fatores, tais como as reações que os pigmentos podem sofrer durante a ingestão e a absorção, a quantidade ingerida e a quantidade de lipídeos presente na pele ou na carne, uma vez que esses fatores determinam a quantidade de carotenoides depositada e, consequentemente, a cor gerada no produto. Assim, a biomassa de $R$. gelatinosus permanece como alternativa viável para a pigmentação de aves de corte, porém requer mais estudos a fim de elucidar importantes pontos, como a estabilidade dos pigmentos $\mathrm{e}$ as concentrações adequadas para alcançar a cor desejada.

\section{CONCLUSÃO}

A concentração da biomassa de $R$. gelatinosus utilizada na ração de frangos de corte influenciou a cor dos produtos cárneos. Os efeitos da biomassa sobre a cor foram mais evidentes na pele da coxa e na carne do peito, onde o produto, até a concentração de $2 \mathrm{~g} / \mathrm{kg}$ de ração, promoveu aumento da tonalidade amarela e da luminosidade e, na concentração de $3 g / k g$ de ração, promoveu aumento da tonalidade vermelha. A presença da biomassa nas rações piorou a conversão alimentar, mas não influenciou os demais parâmetros de desempenho zootécnico.

\section{AGRADECIMENTOS}

À Fundação de Amparo à Pesquisa do Estado de São Paulo pelo financiamento do projeto e concessão de bolsa de mestrado (Processos $\mathrm{N}^{\circ}$ 2011/50274-4 e 2010/04090-6). 


\section{REFERÊNCIAS}

AKIBA, Y.; SATO, K.; TAKAHASHI, K. et al. Meat color modification in broiler chickens by feeding yeast Phaffia rhodozyma containing high concentrations of astaxanthin. J. Appl. Poultry Res., v.10, p.154-161, 2001.

BHOSALE, P.; BERNSTEIN, P.S. Microbial xanthophylls. Appl. Microbiol. Biotechnol., v.68, p.445-455, 2005.

BRASIL. Portaria $\mathrm{n}^{\circ} 210$ de 10 de Novembro de 1998. Diário Oficial da República Federativa do Brasil, Poder Executivo, Brasília, DF, 26 nov. 1998. Seção 1, p.226.

CASTAÑEDA, M.P.; HIRSCHLER, E.M.; SAMS, A.R. Skin pigmentation evaluation in broilers fed natural and synthetic pigments. Poult. Sci., v.84, p.143-147, 2005.

CHEN, B.H.; YANG, S.H. An improved analytical method for the determination of carotenes and xanthophylls in dried plant materials and mixed feeds. Food Chem., v.44, p.61-66, 1992.

DSM Guidelines for egg yolk pigmentation with carophyll. DSM Nutritional Products, 2004. Disponível em: <http://www.christa.bg/files/ Catalogue/105.pdf $>$. Acessado em: 7 mai. 2012.

LAI, S.M.; GRAY, J.I.; FLEGAL, C.J. Deposition of carotenoids in eggs from hens fed diets containing saponified and unsaponified oleoresin paprika. J. Sci. Food Agric., v.72, p.166-170, 1996.

LIMA, K.F.L.; PONSANO, E.H.G.; PINTO, M.F. Cultivation of Rubrivivax gelatinosus in fish industry effluent for depollution and biomass production. World J. Microbiol. Biotechnol., v.27, p.2553-2558, 2011.

LIUFA, W.; XUFANG, L.; CHENG, Z. Carotenoids from Alocasia leaf meal as xanthophyll sources for broiler pigmentation. Trop. Sci., v.37, p.116-122, 1997.

MELENDEZ-MARTÍNEZ, A.J.; VICARIO, I.M.; HEREDIA, F.J. Estabilidad de los pigmentos carotenoides em los alimentos. Arch. Latinoam. Nutr., v.54, p.209-215, 2004.

PÉREZ-VENDRELL, A.M.; HERNANDEZ, J.M.; LLAURADO, L. et al. Influence of source and ratio of xanthophylls pigments on broiler chicken pigmentation and performance. Poult. Sci., v.80, p.320-326, 2001.
POLONIO, L.B.; PONSANO, E.H.G.; PINTO, M.F. et al. Utilisation of bacterial (Rubrivivax gelatinosus) biomass for egg yolk pigmentation. Anim. Prod. Sci., v.50, p.1-5, 2010.

PONSANO, E.H.G.; LACAVA, P.M., PINTO, M.F. Isolation of Rhodocyclus gelatinosus from poultry slaughterhouse wastewater. Braz. Arch. Biol. Technol., v.45, p.445-449, 2002a.

PONSANO, E.H.G.; PINTO, M.F.; GARCIA NETO, M. et al. Evaluation of Rhodocyclus gelatinosus biomass for broiler pigmentation. J. Appl. Poultry Res., v.11, p.77-82, 2002b.

PONSANO, E.H.G.; LACAVA, P.M., PINTO, M.F. Chemical composition of Rhodocyclus gelatinosus biomass produced in poultry slaughterhouse wastewater. Braz. Arch. Biol. Technol., v.46, p.143147, 2003.

PONSANO E.H.G.; PINTO, M.F.; GARCIA-NETO, M. et al. Performance and color of broilers fed diets containing Rhodocyclus gelatinosus biomass. Braz. J. Poultry Sci., v.6, p.237-242, 2004.

PONSANO, E.H.G.; PAULINO, C.Z.; PINTO, M.F. Phototrophic growth of Rubrivivax gelatinosus in poultry slaughterhouse wastewater. BioresourceTechnol., v.99, p.3836-3842, 2008.

ROSTAGNO, H.S.; ALBINO, L.F.T.; DONZELE, J.L. et al. Tabelas brasileiras para aves e suínos: composição de alimentos e exigências nutricionais. 3.ed. Viçosa: Editora UFV, 2011. 252p.

STATISTICAL Analysis Sistem - SAS Institute Inc. The SAS System, release 9.2. SAS Institute Inc., Cary:NC, 2008.

TOYOMIZU, M.; SATO, K.; TARODA, et al. Effects of dietary Spirulina on meat color in muscle of broiler chickens. Br. Poult. Sci., v.42, p.197-202, 2001.

TYCZKOWSKI, J., SCHAEFFER, J.L.; HAMILTON, P.B. Measurement of malabsorption of carotenoids in chickens with pale bird syndrome. Poult. Sci., v.70, p.2275-2279, 1991.

ZAR, J.H. Biostatistical analysis. 4.ed. New Jersey: Prentice-Hall, 1999. 663p. 